\title{
The Dualeh Regulations
}

The Government has recently added an amendment to the section of the Disability Living Allowance and Disability Working Allowance Act 1991 relating to lower rate mobility. For the first time, a differentiation has been made in the approach to assessment between those with severe mental disability, from those with severe physical disabilities. The amendment has become known as the Dualeh Regulation. The background history is described and the wider implications considered. The lower rate mobility component (LRMC) of the living allowance, currently at $f 14.90$ a week, is for people who can walk but because of severe mental or physical disabilities need guidance or supervision from another person when walking outdoors in unfamiliar places. It is to this section of the Act that the amendments were added.

\section{The Dualeh decision}

The Social Security and Child Support Commissioners are the specialised part of the Judiciary appointed to determine appeals on law under the Social Security Act 1990 and Child Support Act 1991. Their work involves giving interpretations of the law that are binding on the administrative adjudication and tribunal systems at the levels below them, and remedying procedural injustices in those systems.

Commissioners' decisions are followed in preference to the original Appeal Tribunal's decision and are binding on the decision-makers - those people in the Disability and Carers Service who make the initial decisions on Disbility Living Allowance claims.

In June 2000, a Tribunal of Commissioners held that a pre-lingually deaf person, with severely impaired comprehension of English, would be too frightened or nervous to walk on unfamiliar routes, if they had never done so unaccompanied, and could be entitled to the lower rate component on the grounds of 'fear' or 'anxiety'. To quote from the Tribunal of Commissioners,

'If it is established, first, that fear or anxiety results from the underlying disability, and secondly, that such fear or anxiety is a cause of the inability to take advantage of the faculty of walking on unfamiliar routes, the necessary causal nexus is established between the disability and the inability to take advantage of the faculty and entitlement to LRMC is made out' (Social SecurityAdvisory Committee \& Secretary of State for Work and Pensions, 2002: p.20)

In their ruling, the commissioners made no distinction between physical and mental disorders. In other words, from now on, all applicants could be considered for LRMC solely on the grounds of experiencing 'fear' or 'anxiety' if unaccompanied outdoors in unfamiliar surroundings.

\section{The Government's response to the Dualeh decision}

In a Hansard Report of 7 May 2002, Maria Eagle, the Parliamentary Under-Secretary of State for Work and Pensions, summarised the Government's need to respond as follows;

'There are somewhat inconsistent and different views on the subject, and that decision - the Dualeh decision - held against decisions made by other tribunals. The decision was that fear or anxiety of any severity could count for entitlement in the lower rate mobility component, but the decision did not indicate the precise circumstances in which it might do so. That created uncertainty for our decision makers, who have to decide whether a claimant is eligible...' (Second Standing Committee on Delegated Legislation, 2002)

Ms Eagle explained that people who were blind or pre-lingually deaf would continue to qualify for LRMC. For DLA, cases from applicants with physical disabilities would continue to be assessed on their individual merits. It was in the realm of mental disability that the eligibility criteria required clarification.

As a result of the Dualeh decision, the Government was concerned that there would be an unintended widening of the gateway for DLA LRMC with its cost implications. The Social Security Advisory Committee (SSAC) had reported that a total of 200 additional awards had been made between the period October 2000 to June 2001 as a result of the Tribunal Commissioners' recommendation. This equated to an additional cost of $f 150000$ a year. Over 5 years, the expected cumulative cost would be $\mathrm{f} 2.3$ million.

Two statutory committees, the SSAC and the Disability Living Allowance Advisory Board (DLAAB), advised the Government preceding the introduction of the amendments to the law.

\section{The DLAAB's response}

The DLAAB is a Government advisory body, comprising medical members, lay members and people with physical handicaps (Lucas, 2001). As the adult psychiatric representative to the board, I was able to contribute advice as to the shaping of the documented DLAAB response to the Dualeh decision.

In the DLAAB's opinion, there was difficulty with the use of terms such as fear or anxiety as they could be normal reactions to life events or may be a symptom of mental illness as defined in the ICD-10. We therefore believed that the supervision needs resulting from fear and anxiety should only be considered if they arose directly from an underlying psychiatric condition e.g. previous agoraphobia, agoraphobia as part of 
depressive illness, or some cases of paranoia or schizophrenia (Grahame, 2002).

special articles

\section{The SSAC's response}

The SSAC did not accept that the Commissioners' ruling created confusion for the Decision-Makers, or that it would open up LRMC to people for whom it was not intended (Boyd-Carpenter, 2002).

They had canvassed opinions from 62 organisations including the RNI for the Blind, the RNI for the Deaf, the British Epilepsy Association, the National Phobics Society, Mencap, the National Schizophrenia Fellowship and the Royal College of Psychiatrists. Without providing details of specific responses, the SSAC reported that respondents had generally agreed that 'fear' and 'anxiety' were elastic terms that were no less precise than other terms used in Social Security law, such as 'pain' or 'severe discomfort' that appear elsewhere in DLA legislations, and that the decision-makers could cope with such terms

The SSAC (Social Security Advisory Committee \& Secretary of State for Work and Pensions, 2002) regarded 'the distinction between mental and physical health problems as an artificial historical one rather than a medical one... the distinctions between mental and physical problems are constantly changing'.

The SSAC's concern over the DLAAB's recommendation was that 'by linking claims to the ICD, this represented a further step down the route of establishing a more medicalised model for DLA entitlement, rather than an approach based on a large element of self-reporting.'

\section{The Government's amendment to LRMC}

In the entitlement to LRMC, the following paragraphs were added to the act.

"(7) For the purposes of section 73(1) (d) of the Act, a person who is able to walk is to be taken not to satisfy the condition of being so severely disabled physically or mentally that he cannot take advantage of the faculty out of doors without guidance or supervision from another person most of the time if he does not take advantage of the faculty in such circumstances because of fear or anxiety.

(8) Paragraph (7) shall not apply where fear and anxiety is

(a) a symptom of mental disability; and

(b) so severe as to prevent the person taking advantage of the faculty in such circumstances.

Maria Eagle included a supplement to explain how LRMC would now work on claims of 'fear' or 'anxiety'. If LRMC was based on the grounds of fear or anxiety, then that aspect of the claim would be looked at again when the person's benefit was next re-examined.

In relation to claims of not being mentally ill, but still nervous about going out and would like to have someone with them, the claim would depend on the extent of the nervousness and whether it amounted to a symptom of mental disability. Decision-makers could seek medical guidance on this matter (Eagle, 2002).

\section{The wider perspective}

Since DLA was introduced in 1992, there has been a gradually increasing recognition of the needs of people with mental illness as a separate category from those with physical disability. The latest DLA statistics reveal that the two leading recipients for DLA benefits are now mental health (552 000) and arthritis (480 000), and together these represented $43 \%$ of all causes (Department for Work and Pensions, 2002).

The Dualeh Regulations are a milestone in the differentiation of assessment of those with mental illness from those with severe physical disabilities.

Differentiating the social needs and interests of people with mental illness from those of people with physical illness is an ongoing process. However, beyond the immediate interest in the amendments, there may be a wider perspective.

A constant challenge for the College is in relation to how to make an impact on proposed legislation, in controversial areas, such as the proposed new Mental Health Act. Perhaps we can draw some optimism from the Dualeh regulations, where, I believe, a medical opinion was heard and able to make a positive contribution to the subsequent legislation.

\section{Declaration of interest}

R.L. is psychiatric member of the Disability Living Allowance Advisory Board.

\section{References}

BOYD-CARPENTER, T. (2002) Report from Social SecurityAdvisory Committee 18-21. Norwich: Stationery Office.

DEPARTMENT FOR WORK AND PENSIONS (2002) Disability and Mobility Benefits - February 2002 Quarterly statistical enquiry. London: National Statistics.

EAGLE, M. (2002) Amendment of Regulation 12 of the Social Security (Disability Living Allowance) regulations 1-6. Norwich: Stationery Office.

GRAHAME, R. (2002) Report from Disability Living Allowance Board 24-25. Norwich: Stationery Office.

LUCAS, R. (2001) The Disability Living Allowance Advisory Board. Psychiatric Bulletin, 25, 475-477.

NATIONAL STATISTICS (2002) Disability Care and Mobility Benefits Quarterly

*Richard Lucas Consultant Psychiatrist, St Ann's Hospital, London N15 3TH
Statistical Enquiry - Februrary 2002 London: Department forWork and Pensions.

SECOND STANDING COMMITTEE (2002) Social Security (Disability Living Allowance) (Amendment) Regulations 2002. Hansard (UK Parliament, House of Commons) 7 May 2002, cols. 4-25. http:// www.parliament.the-stationery-

office.co.uk/pa/cm200102/ cmstand/deleg2/st020507/ 20507s01.htm\#end.

SOCIAL SECURITYADVISORY COMMITTEE \& SECRETARY OF STATE FOR WORK AND PENSIONS (2002) The Social Security (Disability Living Allowance) (Amendment) Regulations 2002 (S.I. 2002) No. 648 (Cm 5469) London: Stationery Office. http:// ON DELEGATED LEGISLATION www. offical-documents.co.uk/ document/cm54/5469/5469.htm 